Bencsik, A., Jakubik, M., \& Juhasz, T. (2020). The Economic Consequences of Trust and Distrust in Knowledge-Intensive Organizations. Journal of Competitiveness, 12(3), 28-46. https://doi.org/10.7441/ joc. 2020.03 .02

\title{
THE ECONOMIC CONSEQUENCES OF TRUST AND DISTRUST IN KNOWLEDGE-INTENSIVE ORGANIZATIONS
}

- Andrea Bencsik, Maria Jakubik, Timea Juhasz.

\begin{abstract}
Studies measuring workplace trust in connection with leadership style and leader responsibility have become more and more important in recent years. Interest in the subject has been rising along with the recent introduction of knowledge management systems (KMSs), which has shown to be one of the most important factors of competitiveness. The aim of this research was to examine to what extent leaders of organizations are concerned about the presence of trust and/ or distrust, as well as about the economic consequences of trust and distrust. It also focused on solutions used in KMSs in knowledge-intensive organizations. Based on a model developed by the authors, the significance of a trust-based culture was examined from the viewpoint of economic consequences. Situations were analyzed in which, despite the existence of all knowledgerelated preferences, managers were not concerned about the economic consequences of trust or distrust. To test the system of relations in the model, a questionnaire survey was conducted in two neighboring European countries with different cultures. It has been found out that in most cases, there is a need for the building and/or use of a KMS at a strategic level. Appropriate tools are also used at an operative level (often spontaneously). However, trust as a general cultural prerequisite is often lacking. Businesses do not seem concerned about the consequences of trust and distrust, as related economic impacts are rarely quantified.
\end{abstract}

Keywords: competitiveness, financial consequences, knowledge-intensive SMEs, knowledge management, trust and distrust

JEL Classification: M1, L10, L20, D22, D23

Received: May, 2020

1st Revision: July, 2020

Accepted: July, 2020

\section{INTRODUCTION}

The primary aim of this research is to examine how organizations handle the economic consequences of the presence or absence of trust in knowledge-intensive SMEs. This topic is current, as "Trust has rightly moved from bit player to centre stage in contemporary organizational theory and research" (Chinn et al., 2018; Tan \& Lim, 2009; Paliszkiewicz et al., 2014a). Furthermore, 
while there is a vast literature exploring the key determinants of organizational performance such as labour and capital, in the knowledge economy, the performance of organizations also depends increasingly on a fair and positive working environment, the well-being of employees, engagement of knowledge workers, and on social and relational capital. In the creative economy, collaboration, sharing, and communication are essential bases for new knowledge and innovation (Botsman, 2017; Lencioni, 2017). Consequently, there is an increased need both for trust and for eliminating distrust, the latter of which hinders the knowledge creation process (Ellonen et al., 2008; Kuo, 2013).

We seek to address these needs by filling three gaps in the research. First, a substantial number of papers deal with how knowledge sharing can be made easier and more efficient if trust is present in an organization (Kuo, 2013; Rutten et al., 2016; O’Neill, 2018). Nevertheless, only a few papers have focused on the economic consequences of trust or distrust, and on what a climate of trust means in terms of business management (Bjornskov, 2012; Algan \& Cahuc, 2013; Pols, 2015). Parallel work, parallel tasks, multiple controls, uncertain decisions, and working with ineffectual colleagues who are closely connected to a certain manager all cause profound financial consequences. Second, there have been very few papers dealing with profit and loss in relation to the effects of trust or distrust in knowledge management (KM) strategy building. Third, findings show that in spite of the fact that knowledge-intensive organizations are based on knowledge and trust, studies do not deal with building KM systems (KMS) at a strategic level, nor do they deal with the financial consequences of trust and distrust.

Our main research question is: "Are the financial consequences of trust or distrust important to knowledge-intensive organizations?.” We also formulated the following sub-questions: "What is the level of trust in organizations? Do managers make efforts to build and operate a knowledge management system at a strategic level? Are there elements and methods of KMS in the researched organizations? Does a trustful corporate culture support the successful implementation of these methods?"

The paper has three main parts, with the first of these is a literature review upon which our theoretical model has been based. To test our theoretical model, we have conducted an empirical research with a randomly selected sample of 466 organizations, of which 236 knowledge-intensive SMEs have been identified for further analyses. We then formulated our hypotheses, conducted a quantitative questionnaire, and statistically analysed the data. The discussion of our results show that trust is not considered a factor influencing competitiveness and business success. Only some of the organizations deal with the economic consequences resulting from the absence of trust.

\section{THEORETICAL BACKGROUND}

The proposed theoretical model is based on the concepts of trust, knowledge, and on the theory of organizational knowledge creation of KM. Therefore, to position our research and present our model we briefly discuss how these concepts are defined in the literature as well as current developments. 


\subsection{About trust}

The role of trust in organizational performance has begun to play an important role in micro- and macroeconomics literature, in applied psychology, in human resource management, in intellectual capital literature, and in entrepreneurship studies. The impacts of trust and distrust have been researched broadly, primarily in relation to communication, ethics, commitment, culture and/or other corporate success factors (Rahman et al., 2015; Azman et al., 2013; Ayoko \& Pekerti, 2016). Nevertheless, there have not been many empirical research projects providing quantifiable results. This is especially true regarding studies aimed at quantifying the financial consequences of trust and distrust in knowledge-intensive organizations.

We assume the multifaceted nature of trust and distrust, accepting that there are many problems caused by unconditional, blind trust. Concurring with Rutten el al., (2016), we agree that trust is a two-sided coin. Trust in general is assumed to be a positive concept, whereas blind trust can lead to negative consequences, a finding which has been indicated in previous research (Zanini \& Musante, 2013; Yong \& Jaekvon, 2014; Rahmann et al., 2015) in which a close relationship between trust, knowledge creation and sharing was demonstrated. There is a need for defining trust as a transformational concept rather than a transactional concept. Botsman (2017) argues that "trust is the currency of interactions that lies between us" in our collaborative and sharing economy. She calls for a new definition of trust, as in her view trust as a concept is evolving and it is different in our digital, sharing economy than what it was in the industrial economy.

Because trust is a very complex construct, it is natural that is defined in many different ways. Dalkir (2011) defines trust as follows: "Certainty based on past experience. The trait of trusting; of believing in the honesty and reliability of others. Complete confidence in a person or plan." Similarly, Lazányi (2017) discusses the honesty and reliability of others. They argue that trust capital is valuable for organizations. Lazányi et al. (2017) claim that the issue of trust has long been a critical subject of organization studies, given its centrality in all manners of coordinated human interaction and exchange. Chinn et al. (2018) acknowledge the benefits of trust and focuses on how organizations can create trust. They admit that the theory remains deficient, with major gaps in the research evidence (Lazányi et al., 2017). Nevertheless, Rutten et al. (2016) examine the double-sided nature of trust and argue that trust is not only positive, but it has negative sides as well. In many studies, trust is defined as a tool for successful and efficient organizational cooperation (O’Neill, 2018; Aupers, 2012; Elchardus \& Keere 2013; Achterberg et al., 2015). We believe that both relational trust and personality-based trust are critical in knowledge creation and sharing. However, we argue that in knowledge creation and sharing, some combination of all these different types of trust can be found.

In this paper, we focus on the organizational context of SMEs. As we are moving from a knowledge economy towards a collaborative and creative economy, the role of trust becomes pivotal in generating new knowledge by sharing existing knowledge with others, as well as in innovation. It is critical how leaders and managers foster a context in which trust can flourish and knowledge can emerge. Lencioni (2017) focused on building a cohesive leadership team in an organization. According to the researcher this process starts with building trust among team members. $\mathrm{He}$ argues that when there is trust, conflict is not a problem; it represents a way to achieve consensus. Commitment and accountability are required from a leadership team in order to achieve results 
and organizational goals. The role of leadership and management is critical in organizational knowledge creation and sharing. It is a fact that if the level of trust increases within a group, it improves individual and organizational performance alike. Nevertheless, the negative consequences of excessive trust must be kept in mind as well.

Since the impacts of trust are usually not expressed in direct numbers, quantification in concrete cases is a significant challenge. In recent years, a vast amount of research has been published discussing the relationship between knowledge creation, sharing and trust (Paliszkiewicz \& Koohang, 2013; Paliszkiewicz et al., 2014b; Alsharoa et al., 2017; Sankowska, 2013; Killingsworth et al., 2016). The studies confirm that trust affects the process of knowledge sharing, the quality and depth thereof, and consequently trust can be closely associated with the building and operation of KMS. Before presenting our theoretical model, we review the concept of knowledge, and organizational knowledge creation processes.

\subsection{Knowledge and knowledge creation process in organizations}

Knowledge is both tacit and explicit at the same time (Polanyi, 1966). It is dynamic, relational, social and individual. Knowledge is a human action that depends on context.

KM literature shows different attempts to classify knowledge (Jakubik, 2007). As an example, Ford (2003) viewed knowledge in six ways: (1) knowledge versus data and information; (2) levels of knowledge (object, individual, group or community, organizational, and public); (3) types of knowledge (explicit and tacit); (4) knowledge processes (socialization, externalization, combination, and internalization); (5) business processes (knowledge generation, codification, transfer, and use); and (6) KM business practices (KMS, documentation, communities of practice, mentoring, storytelling, and accidents).

There are several discourses and assumptions about knowledge. Nevertheless, there is a need to understand knowledge from the practice-based perspective (constructivist and dialogic discourses). In this paper, we adopt the practice-based theory of knowledge where organizations are distributed knowledge systems, where knowledge is embedded in the work activities of people, where knowledge is tacit and explicit at the same time, socially constructed, and contestable (Linand \& Hsiao, 2014).

How is new knowledge created in an organizational context? What are the processes and conditions of knowledge creation? What is the role of trust in knowledge creation and knowledge sharing? How has the theory of organizational knowledge creation evolved? These questions have gained importance in the knowledge economy (Zanini \& Musante, 2013; Botsman, 2017; Lencioni, 2017). Business processes and knowledge creation processes are closely related. Gonzales \& Martins (2017) identified four phases of knowledge processes: (1) knowledge generation, (2) knowledge codification and coordination, (3) knowledge transfer, and (4) knowledge use. In this paper, the focus is on knowledge generation, transfer, and use. Ford (2003) argues that if distrust is present, then knowledge generation will be blocked, as fear, cynicism, wariness will prevent an individual from sharing required knowledge or information'.

To position this research, it is vital to understand the advancement of the generations of KM. The theory of knowledge creation has developed into five distinctive phases (Jakubik, 2011): 
(1) mid-1990s, the foundation of the theory (Nonaka, 1994; Nonaka \& Takeuchi, 1995); (2) the unified model of dynamic knowledge creation by Nonaka et al. (2000); (3) the context and the roles of leaders and managers are emphasized (von Krogh et al., 2000a); (4) the focus is on the justification process of organizational knowledge (von Krogh \& Grand, 2000; von Krogh et al., $2000 \mathrm{~b}$ ); and (5) the need for a new theory of the knowledge-based firm, the focus needs to be on situation, process, action, and change (Nonaka et al., 2008). Similarly, Serenko (2013) identifies four generations of KM:

- prior to mid-1990s: techno-centric view of knowledge processes, knowledge sharing is initiated and driven by management, focus on explicit knowledge

- mid-1990s to early 2000s: human factors and intellectual capital become important, organizational learning, social and cultural aspects, knowledge sharing processes are initiated and driven by individual employees as their daily practices

- early 2000s-2013: culture and contextual aspects become important, social learning, collaboration, democratization of knowledge, involvement, managing knowledge as a flow

- since 2013: knowledge is seen as a relationship, a shift to the mind economy and intangible knowledge, and to networking organisations.

We position our research in the fourth generation of KM. Business environment in the creative economy demands more attention to knowledge, innovation, and trust (Zanini \& Musante, 2013; Botsman, 2017; Lencioni, 2017).

Most studies show that trust is closely related to the performance of organizations. These studies confirm their claims from a number of perspectives, but none of them provides a quantitative statement of the impact of the lack of trust or excessive trust on organizational performance. We encountered a particularly low number of studies that would specifically focus on the logic of $\mathrm{KM}$ processes to verify existing relationships. In spite of many valuable studies, the tangible impact cannot be shown for managers that would provide sufficient evidence to adequately assess the consequences of this relationship. We aim to respond to this need by presenting our theoretical model and test the relationships of its elements.

\subsection{Theoretical model}

Based on our literature review about trust, knowledge, and knowledge creation processes, we propose a theoretical model (Figure 1). This model is an illustration of how trust-based knowledge could lead to business success. The three phases of trust-based knowledge sharing are engaging, evolving, and employing. 


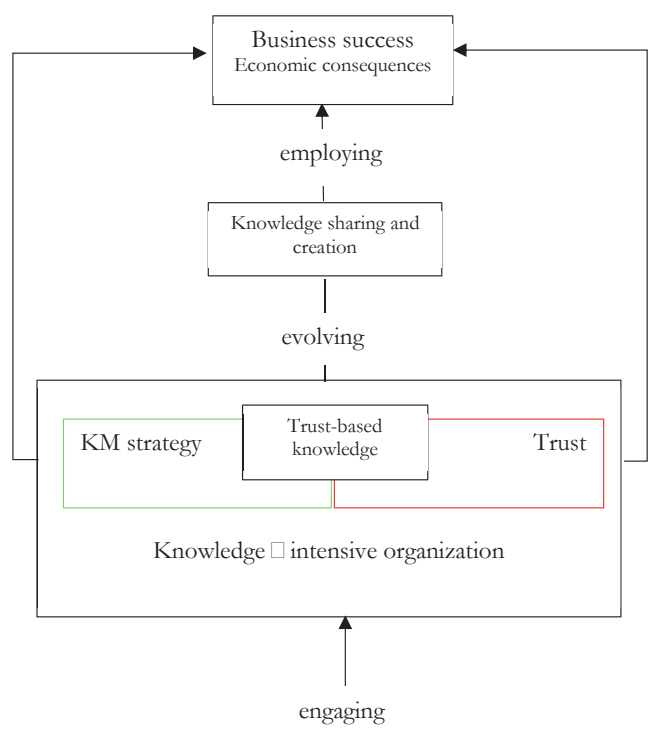

Fig. 1 - Initial model. Source: own research

Engaging a person in a business context is the first phase. This is critical because in the knowledge economy, knowledge workers engage in a business context only if they find the organization's values, culture, and goals attractive. This is a trust between an individual and the organization that could be based as much on rationalities (calculative, cognitive trust) as on emotions (relational trust) (Achterberg, 2015; Zanini \& Musante, 2013). Nowadays, emotional bonds and values are more critical for knowledge workers, especially digital natives and generations $\mathrm{Y}$, $\mathrm{Z}$ members, when they join an organization. However, we acknowledge that different types of trust could play a role in engaging in organizational contexts.

Evolving refers to the dynamic, dialectic nature of the on-going knowledge creation and sharing that have two simultaneous processes. One is exploring and experiencing the business context. Nonaka (1994) calls this phase 'socialization' in his SECI process of knowledge creation. In this phase, the person learns about organization processes and people. Here, relational and personality-based trust plays an important role because this is the phase when people actively interact with each other. Emotion enters into the relationship between parties because frequent, longer-term interaction leads to the formation of attachments based upon reciprocated interpersonal care and concern (Achterberg, 2015).

This process is based on perceptions, intuitions, trust, care, love, experience, and collaboration. When these conditions exist, learning happens, and knowledge is generated and shared between people. We concur with Polanyi (1966) in that there is no dichotomy between tacit and explicit knowledge because they are both dimensions of knowledge and they do not exist without one other. Therefore, we argue that in this phase, different types of knowledge are created and shared: social and individual, tacit and explicit, embodied and embedded, practical and theoretical, and so on. 
The other process is enabling and emerging. When leaders and managers (Nonaka, et al., 2000; Kraft et al., 2015; Lencioni, 2017) enable the context of knowledge creation and sharing, then different types of knowledge will emerge. Furthermore, we argue that the learning process of exploring and experiencing cannot be separated from enabling and emerging because these processes are happening at the same time. As an outcome of these knowledge creation processes, trust-based knowledge will evolve.

Employing is the third phase. As in the creative economy knowledge, it is the main source of the competitive advantage of organizations, it is not enough to share and create knowledge, knowledge needs to be employed, used to create financial value for the organization and for society. The organizations that are not able to create, utilize, and extract value from their knowledge will not be successful. We concur with Gonzales \& Martins (2017) who believe that the only sustainable advantage for a firm comes from what it collectively knows, how efficiently it uses what it knows, and how readily it acquires and uses new knowledge. Next, we present our hypotheses for testing our theoretical model.

The comparison of the two countries with different cultures (Hungary and Slovakia) is interesting because we were curious to see if the differences in the power distance index, found by Hofstede et al. (2010), and also characterizing trust, is reflected in the thinking of the organizational management regarding the handling of the consequences of trust. The cultural characteristics are shown in Figure 2.

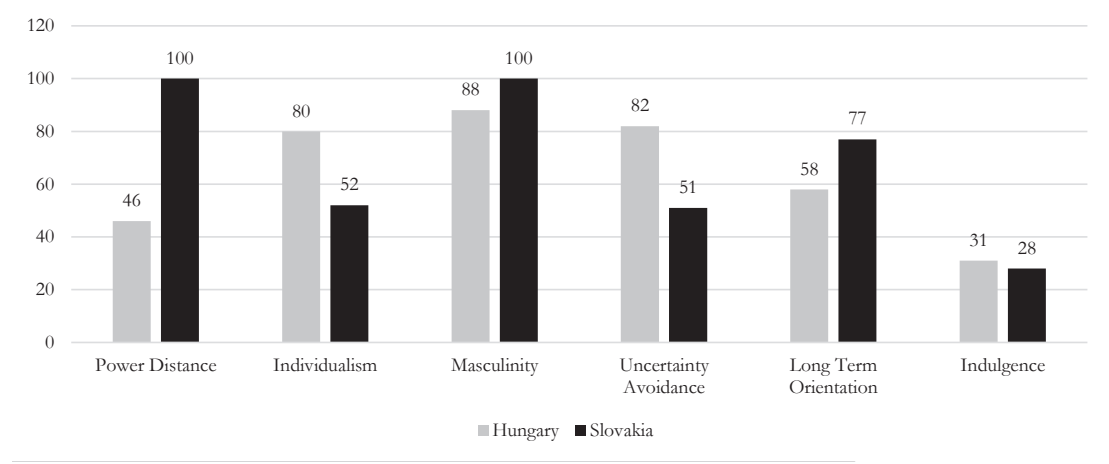

Fig. 2 - Cultural characteristics of Hungary and Slovakia. Source: Hofstede et al. (2010)

To sum up, in this part of the paper, we conducted a literature review, based on which we created our theoretical model (Figure 1). Next, we present our quantitative research about the financial consequences of the presence or absence of trust.

\section{RESEARCH OBJECTIVE, METHODOLOGY AND DATA}

In 2018, complex (stratified and random) sampling was applied using probabilistic sampling. The stratification was done on a geographical basis, with a Hungarian and Slovak territorial breakdown, targeting the most developed regions of the two countries. Based on the lists provided by national Statistical Offices, we selected 3,000-3,000 organizations and sent the link to the 
on-line questionnaire. Respondents answered 35 questions anonymously, 4 of which were open questions and the rest were closed, with a 5-point Likert scale. Each of the returned questionnaires was usable, which means an approximately $7-8 \%$ willingness to fill in. A total of 466 SMEs filled in the on-line questionnaires, which were available on kerdoivem.hu. 231 Hungarian and 235 Slovak organizations answered. SPSS 25 program was used for the analysis. The questionnaire included identical questions in both countries. We used closed questions with nominal and metric scales. The themes of the questionnaire are presented in Table 1.

Tab.1 - Structure of the questionnaire Source: own research

\begin{tabular}{|c|c|c|c|}
\hline $\begin{array}{l}\text { 1. question } \\
\text { group }\end{array}$ & 2. question group & 3. question group & 4. question group \\
\hline $\begin{array}{l}\text { Organizational } \\
\text { specification: } \\
\text { Location and } \\
\text { size of the } \\
\text { organisation } \\
\text { Industry clas- } \\
\text { sification } \\
\text { Ownership } \\
\text { structure }\end{array}$ & $\begin{array}{l}\text { Knowledge characteriza- } \\
\text { tion within organiza- } \\
\text { tions } \\
\text { Importance of knowl- } \\
\text { edge within the organi- } \\
\text { zation } \\
\text { Utilization of knowl- } \\
\text { edge, its integration into } \\
\text { the system } \\
\text { The nature of knowl- } \\
\text { edge, its relevance to the } \\
\text { market } \\
\text { Intra-organizational } \\
\text { knowledge development }\end{array}$ & $\begin{array}{l}\text { Trust in organiza- } \\
\text { tional practices } \\
\text { Defining trust } \\
\text { within the organi- } \\
\text { sation } \\
\text { Elements of } \\
\text { a system of trust } \\
\text { within the organi- } \\
\text { zation } \\
\text { Characteristics of } \\
\text { trust within the } \\
\text { organization }\end{array}$ & $\begin{array}{l}\text { Functioning of the culture } \\
\text { of trust and its economic } \\
\text { impacts } \\
\text { Conditions for building } \\
\text { a relationship of trust } \\
\text { within the organizational } \\
\text { culture } \\
\text { Advantages of trust within } \\
\text { the organizational culture } \\
\text { Consequences of the pres- } \\
\text { ence or absence of trust }\end{array}$ \\
\hline
\end{tabular}

The statistical methods included frequency, mean and standard deviation, cluster, factor and regression analyses. The regression calculation was based on the bivariate linear regression. By applying the linear regression, a path model was formed and we examined whether there was a relationship between the elements of our logical model. The above-mentioned statistical methods provided an opportunity to explore deeper correlations as well. Besides organizational features, the role, nature and importance of knowledge were analysed first.

Tab. 2 - Features of the research sample. Source: own research

\begin{tabular}{|l|l|l|}
\hline Features & Hungarian & Slovak \\
\hline Company size & 26 & 60 \\
\hline Micro & 46 & 74 \\
\hline Small & 159 & 101 \\
\hline Medium-sized & 131 & 121 \\
\hline Ownership & 131 \\
\hline Exclusively Hungarian/Slovak & \multicolumn{2}{|l|}{} \\
\hline
\end{tabular}




\begin{tabular}{|l|l|l|}
\hline Mixed & 26 & 53 \\
\hline Exclusively foreign & 74 & 61 \\
\hline Activities & \multicolumn{2}{l|}{} \\
\hline Knowledge-intensive & 132 & 104 \\
\hline Labour intensive & 86 & 108 \\
\hline Capital intensive & 11 & 21 \\
\hline
\end{tabular}

The organizations of the two countries differed significantly in their opinion regarding the importance of knowledge (Pearson's Chi-square: 8.908 df: 2 sign.: .012 p<0.05). More than half of the Hungarian companies (57.6\%) indicated knowledge-intensive activities, while Slovak organizations indicated mostly labour intensity (46.4\%). Next, further investigation focuses on the 236 knowledge-intensive SMEs (highlighted in Table 2) because we assumed that in these firms, the economic consequences of trust or distrust are the most critical ones.

\subsection{Model of hypotheses}

For testing the theoretical model (Figure 1), we developed the following hypotheses:

Hypothesis 1/a: In knowledge-intensive organizations, the need for operation based on common knowledge (KMS) appears at a strategic level.

Hypothesis 1/b: Creating trust-based knowledge (creating new knowledge) and using trust-based knowledge (knowledge sharing) requires a demand for knowledge at a strategic level in an organisation.

Hypothesis $1 / \mathrm{c}$ : Trust climate and a culture of trust are typical for knowledge-intensive organisations.

Hypothesis 2/a: The presence of trust in an organization is a precondition for knowledge creation and sharing.

Hypothesis 2/b: Organizational trust is a prerequisite for managing KMS building at a strategic level.

Hypothesis 3: Knowledge-intensive organizations do not deal with the economic impacts of trust, regardless of whether they formulate a need for KMS building at a strategic level or not.

Hypothesis 4: Although the requirement of $\mathrm{KM}$ is phrased at a strategic level, the lack of trust is not followed and its economic impacts are not taken into consideration.

Hypothesis 5: In order to utilize trust-based knowledge systematically (sharing of trust-based knowledge and knowledge creation), the management deals with the financial consequences of the presence or absence of trust in order to achieve competitive advantage.

Figure 3 presents the model of hypotheses aligned with the theoretical model (Figure1). 


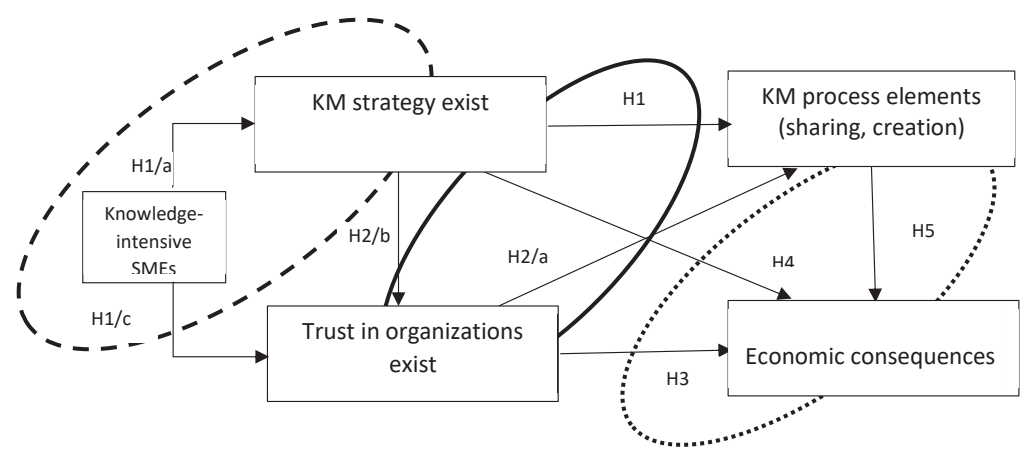

Fig. 3 - Hypotheses model. Source: own research

The three ellipses reflect the logic of the theoretical model (Figure 1), its steps.

Engaging - Ellipse1 means the commitment between the organization and the individual, the incorporation of knowledge into the organization. Trust building between the individual and the organization.

Evolving - Ellipse 2 is the phase of development, knowledge creation and sharing between individuals within the organization. Trust, collaboration and joint learning are dominant here.

Employing - Ellipse 3 is the utilization of knowledge, providing competitive advantage for the organization.

The statistical analyses had the following steps:

1. The first assumption was that in knowledge-intensive organizations where KM is dealt with at a strategic level, trust is important and is also a part of corporate culture. To test the assumption, the notion of trust, as a dependent variable, was defined through Principal component analysis.

2. The second assumption was that organizations in which KM is part of the strategy (bearing in mind the relationship to trust) are concerned about the financial consequences of the lack of trust.

3. The third assumption was the presence of organizational trust, it was also examined whether businesses, regardless of the existence of the KM strategy, deal with the financial impacts of the lack of trust.

4. In order to demonstrate the relationship with trust, it was also examined (fourth assumption) whether KM processes (primarily knowledge sharing and creation) are more intensive in the presence of trust. The negative value indicates that the presence of trust increases the presence of KM elements.

5. In the next step, (fifth assumption) it was examined whether KM process elements are affected in the presence of the KM strategy. Since the principal component describing KM 
process elements in the sample basically suggests less knowledge sharing and new knowledge creation, the negative beta value indicates that the more KM is included in the strategy, the more typical is the presence of knowledge sharing and creation.

6. Last, it was analysed (sixth assumption) whether the financial consequences of the lack of trust are dealt with in organizations where KM process elements are present.

\section{RESULTS}

The regression analysis showed that the presence of KM process elements explains managerial thinking focusing on the economic impacts arising from low trust levels only to a minimum extent. The results of the analyses are shown in Table 3.

Tab. 3 - The results of the analyses Source: own research

\begin{tabular}{|c|c|c|c|c|c|c|}
\hline \multicolumn{2}{|c|}{ Model } & \multicolumn{2}{|c|}{$\begin{array}{l}\text { Unstandardized } \\
\text { Coefficients }\end{array}$} & \multirow{2}{*}{$\begin{array}{l}\text { Standardized } \\
\text { Coefficients } \\
\text { Beta }\end{array}$} & \multirow[t]{2}{*}{$\mathrm{t}$} & \multirow[t]{2}{*}{ Sig. } \\
\hline & & $\mathrm{B}$ & Std. Error & & & \\
\hline \multirow[t]{2}{*}{1} & (Constant) & 3.767 & .063 & & 59.576 & .000 \\
\hline & Trust in the organization & .239 & .063 & .239 & 3.769 & .000 \\
\hline \multirow[t]{2}{*}{2} & (Constant) & 3.489 & .138 & & 25.272 & .000 \\
\hline & $\begin{array}{l}\text { Do they deal with the } \\
\text { economic consequences } \\
\text { arising from the KM } \\
\text { strategy? }\end{array}$ & .142 & .062 & .147 & 2.273 & .024 \\
\hline \multirow[t]{2}{*}{3} & (Constant) & -.938 & .121 & & -7.723 & .000 \\
\hline & $\begin{array}{l}\text { Do they deal with the } \\
\text { economic consequences } \\
\text { arising from trust? }\end{array}$ & .479 & .055 & .496 & 8.731 & .000 \\
\hline \multirow[t]{2}{*}{4} & (Constant) & 6.080 & .062 & & .000 & 1.000 \\
\hline & $\begin{array}{l}\text { Are KM processes more } \\
\text { intensive in the presence } \\
\text { of trust? }\end{array}$ & -.319 & .062 & -.319 & -5.157 & .000 \\
\hline \multirow[t]{2}{*}{5} & (Constant) & 3.767 & .061 & & 61.537 & .000 \\
\hline & $\begin{array}{l}\text { Are KM process elements } \\
\text { affected in the presence of } \\
\text { the KM strategy? }\end{array}$ & -.341 & .061 & -.341 & -5.551 & .000 \\
\hline \multirow[t]{2}{*}{6} & (Constant) & .325 & .138 & & 2.358 & .019 \\
\hline & $\begin{array}{l}\text { Do they examine what } \\
\text { economic consequences } \\
\text { the presence or the lack } \\
\text { of trust have on their } \\
\text { organization? }\end{array}$ & -.660 & .062 & -.172 & -2.666 & .000 \\
\hline
\end{tabular}




\subsection{Testing the hypotheses}

We test the theoretical model and the hypotheses by the regression analysis. Figure 4 shows the hypotheses and the calculated correlations between the elements of the model.

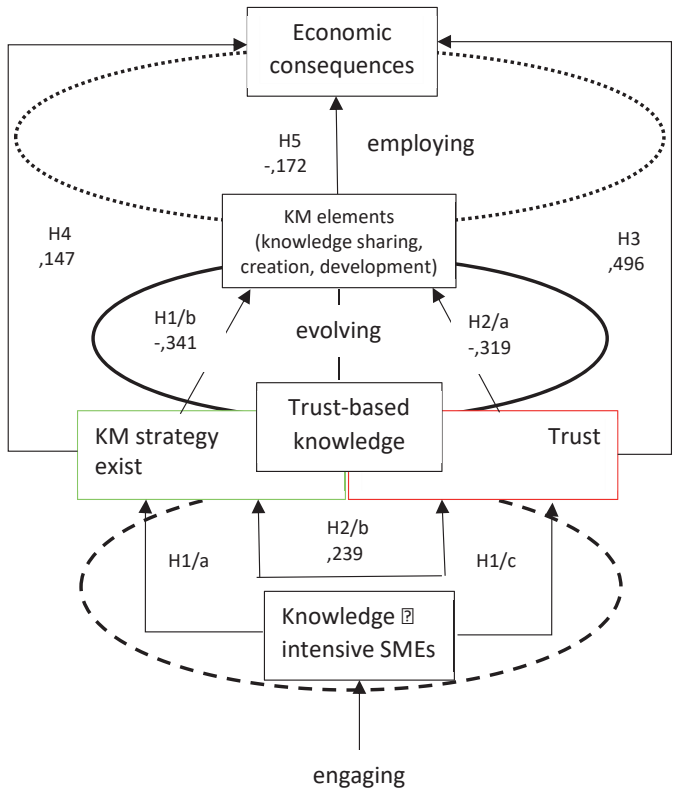

Fig. 4 - Combination of the initial model and the bypotheses model. Source: own research

$\mathrm{H} 1 / \mathrm{a}, \mathrm{b}$ and $\mathrm{c}$ - The results show that knowledge-intensive SMEs typically deal with the importance of knowledge (H1/a) at a strategic level and they use numerous solutions for managing knowledge. They are typically open to any form of knowledge, its creation, transfer and preservation $(\mathrm{H} 1 / \mathrm{b})$. Table 4 shows the average values and deviation regarding the statements of the investigated knowledge-intensive organization.

Tab. 4 - The role of knowledge and its management. Source: own research

\begin{tabular}{|l|l|l|l|l|}
\hline Statement & $\mathrm{N}$ & & Mean & $\begin{array}{l}\text { Std. } \\
\text { deviation }\end{array}$ \\
\hline & Valid & Missing & & \\
\hline It has a significant role in the strategy. & 236 & 0 & 3.77 & .998 \\
\hline $\begin{array}{l}\text { Arising from the strategy, it is manifested in } \\
\text { operative tasks. }\end{array}$ & 236 & 0 & 3.67 & 1.003 \\
\hline $\begin{array}{l}\text { It is not articulated at a strategic level, but every- } \\
\text { one knows that this is a pillar of our operation. }\end{array}$ & 236 & 0 & 2.79 & 1.266 \\
\hline $\begin{array}{l}\text { We use several methods to create, transfer or } \\
\text { preserve knowledge. }\end{array}$ & 236 & 0 & 3.86 & .961 \\
\hline
\end{tabular}




\begin{tabular}{|l|l|l|l|l|}
\hline $\begin{array}{l}\text { The management insists on this kind of ap- } \\
\text { proach, but the staff does not engage in it. }\end{array}$ & 236 & 0 & 2.16 & 1.034 \\
\hline $\begin{array}{l}\text { Our corporate culture does not support taking } \\
\text { the management's efforts seriously. }\end{array}$ & 236 & 0 & 1.96 & 1.016 \\
\hline $\begin{array}{l}\text { It is more important for the staff than for the } \\
\text { management. }\end{array}$ & 236 & 0 & 2.30 & 1.063 \\
\hline $\begin{array}{l}\text { The daily challenges keep us busy and the role of } \\
\text { knowledge remains in the background. }\end{array}$ & 236 & 0 & 2.15 & 1006 \\
\hline
\end{tabular}

By rotation with the Varimax method, two factors were formed. The reliability of scales was examined with Cronbach's alpha, based on which all values were acceptable (Cronbach's alpha > 0.5): (1) Characteristics of organizations not managing knowledge at a strategic level (.780); (2) Characteristics of organizations managing knowledge at a strategic level (Cronbach's alpha: .679). With the help of the factors, three clusters were created (Table 5).

Tab. 5 - Final cluster centres. Source: own research

\begin{tabular}{|l|l|l|l|}
\hline Propositions & Cluster & & \\
\hline & 1 & 2 & 3 \\
\hline Organizations not managing knowledge at a strategic level & 1.05348 & -.62089 & -.38418 \\
\hline Organizations managing knowledge at a strategic level & -.03759 & .56566 & -1.58893 \\
\hline
\end{tabular}

There were 82 organizations in the first, 115 in the second, and 39 in the last cluster (H1/a). It was shown that knowledge-intensive organizations deal with KMS building at a strategic level, and the elements of a KM process also appear at an operational level. Based on the above, H1/a and $\mathrm{H} 1 / \mathrm{b}$ were proved. Concerning the variables describing trust, it could be concluded that, with the exception of one case, there was a significant correlation between trust and pursuing knowledge-intensive activities. Thus, $\mathrm{H} 1 / \mathrm{c}$ was proved.

$\mathrm{H} 2 / \mathrm{a}$ and $\mathrm{b}$ - In the case of knowledge-intensive businesses, whether KM can deal with the absence of trust at a system level was examined, namely, whether the elements of a KM process are present in everyday activities (H2/a). 61\% of knowledge-intensive SMEs considered trust a necessary prerequisite, $24 \%$ were uncertain about it, and $14.8 \%$ did not consider it necessary. $45.1 \%$ of organizations not dealing with $\mathrm{KM}$ at a strategic level (first cluster) were unsure that trust is a prerequisite for managing knowledge at a strategic level. $79.1 \%$ of companies in cluster 2 considered a trust-based culture to be a prerequisite for articulating KMS building in the strategy (H2/b). Businesses that do not deal with KMS building at a strategic level (cluster 3) were of the same opinion (61.0\%). Based on these results, hypotheses $\mathrm{H} 2 / \mathrm{a}$ and $\mathrm{b}$ were proved.

$\mathrm{H} 3$ and $\mathrm{H} 4$ - The research also examined whether the lack of trust and its financial impacts are ever taken into account by the knowledge-based organizations involved in the research (H3). $69.5 \%$ of companies did not really deal with it; $22.0 \%$ were equivocal, and only $8.5 \%$ took it into account knowingly and systematically. The Slovak and Hungarian organizations did not differ from each other in this regard (Pearson's Khi-square: 1.008, df: 2 sign.: .604 p>0.05). 
A one-way ANOVA proved that in knowledge-intensive organizations in which losses arising from the lack of trust are taken into consideration KM plays a significant role in the strategy (average 3.46). However, it is interesting to note that the importance of KMS building at a strategic level (average 3.9) can also be observed in organizations that do not deal with the economic consequences of the loss of knowledge resulting from the lack of trust (H4).

The organizations in the three clusters specified above did not differ from each other regarding whether they evaluate the consequences of the lack of trust. $12.2 \%$ of all the organizations dealing with knowledge at a strategic level were dealing with these consequences. The same proportion among those with a non-strategic knowledge approach amounted only to $5 \%$, and about three-quarters of these companies did not at all deal with the possibility of such economic losses. In view of the above, hypotheses 3 and 4 were proved.

H5 - A correlation analyses showed that if knowledge transfer/sharing and creation are a part of everyday activities and are incorporated into corporate culture, the financial consequences of the presence or absence of trust can be assessed. Nevertheless, the correlation was rather weak (-.172). Nor can the significance be proved in the organizations where knowledge transfer/sharing and creation are not present. $\mathrm{H} 5$ can be proved in those cases in which knowledge-intensive SMEs incorporate the methods and tools of trust-based knowledge creation and sharing into their culture.

With this presentation of the testing of the hypotheses with statistical analyses, we now proceed to a discussion of the results of our research.

\section{DISCUSSION}

Our research is in line with previous studies that have examined the impact of trust upon organizational performance (Achterberg et al., 2014; Yong \& Jaekwon, 2014; Rahmann et al., 2015; Chinn et al., 2018; Alsharoa et al., 2017; Paliszkiewicz \& Koohang, 2013; Paliszkiewicz et al., 2014b; Sankowska, 2013; Killingsworth et al., 2016; Lencioni, 2017).

The model corresponds to emerging trends in the business environment and it underlines the necessary shift in the knowledge-creation paradigm toward constructivist and dialogic paradigms, in contrast with Nonaka (1994) and Nonaka et al.'s (2000) functionalist paradigm (Linand \& Hsiao, 2014; Jakubik, 2011). The model is dynamic, dialectic, and evolutionary, and it is based on the unity rather than the multivalency of different types of knowledge.

In knowledge-intensive organizations, the incorporation of a KMS into the strategy is a basic need. Koohang \& Paliszkiewicz (2013) and Killingsworth et al. (2016) confirmed similar results for Western societies. Nevertheless, in Central and Eastern European countries, in our case in both countries, this is not automatic at all. In most companies, knowledge is less important, and more capital-intensive or labour-intensive activities are focused upon (Table 2).

Our research results also show that knowledge-intensive organizations are not unified in how important they consider the presence of a trust culture as a prerequisite for dealing with their KMS at a strategic level, and as a precondition for successfully functioning KMS elements. This result is in line with previous research results (Paliszkiewicz et al., 2014a; Paliszkiewicz et al., 2014b). 


\section{CONCLUSION}

The aim of our research was to examine to what extent the leaders of organizations are concerned about the presence of trust and/or distrust, and about the economic consequences of trust and distrust. It also focused on solutions used in KMSs in knowledge-intensive organizations. Based on a model developed by the authors, the significance of a trust-based culture was examined from the viewpoint of its economic consequences (Figure 4). This research paper sought to answer the primary research question of whether the economic consequences of trust or distrust are important for knowledge-intensive SMEs. The theoretical model was created on the basis of the literature review of the main concepts and trends in KM (Table 1), following which simple and complex statistical methods were applied to test the correlations between the elements of the model and to prove the hypotheses. From the 236 knowledge-intensive SMEs, only 115 deal with $\mathrm{KM}$ at a strategic level. $12.2 \%$ of these deal with the consequences of losses resulting from the absence of trust theoretically. This represents 14 organizations in total, which is only approximately $6 \%$ of the original sample. Surprisingly, trust was not considered as a factor influencing competitiveness and business success. Despite the cultural differences, we did not find any significant differences between the organizations in the two countries studied.

We intended to fill the research gap regarding the financial consequences of the relationship between trust and knowledge acquisition and sharing, with three main contributions represented in this study. First, the work contributes to the body of research on trust in an organizational context, as only few papers have focused on the economic consequences of trust or distrust; we also investigated what a trusting climate means in terms of business management. Second, there have been very few papers dealing with profit and loss in relation to the effects of trust or distrust on KM strategy building. Third, while findings have shown that in spite of the fact that knowledgeintensive organizations are based on knowledge and trust, studies have not significantly dealt with building KM systems (KMS) at a strategic level nor with the economic consequences of trust and distrust.

Furthermore, we believe that the theoretical model (Figure 1) contributes to a better understanding of the role of trust, knowledge generation, and knowledge development in an organizational context.

The researchers recognize the practical, managerial implications of the results presented. Knowledge-intensive businesses have shown that already understand the need for KM and to incorporate this need into their strategy; however, they generally do not create conditions for its development and functioning. In the researched SMEs, trust is not yet considered as an important criterion, though it is an inevitable prerequisite for a knowledge-sharing culture, new knowledge creation and knowledge preservation. At the same time, the results also indicate that innovation cannot yet be considered an urgently needed daily concern in the SMEs involved in this research. Thus far, trust culture unfortunately has not been considered important by businesses, as they seem unaware of the economic consequences. Much has to be done in social and economic terms to create an atmosphere of post-socialist thinking and behaviours so that the retention of knowledge is fostered and distrust disappears in Central European countries. There is a need for a modern, flexible, value- and trust-based management and leadership thinking, which manifests itself in a culture supporting the successful operation of businesses and their mutual goals. 
The major limitation of the research was that the researched SMEs were not willing to provide numerical economic data. Consequently, accurate numerical information cannot be provided regarding the economic consequences of trust or distrust. Another limitation was the lack of willingness of organizations to fill in the questionnaire, and since it was a self-administered survey, the honesty of the responses could not be controlled during completion.

\section{References}

1. Achterberg, P., Koster, W., \& Waal, J. (2015). A science confidence gap: Education, trust in scientific methods, and trust in scientific institutions in the United States 2014. Public Understanding of Science, 24 (12), 1-17. https://doi.org/10.1177/0963662515617367

2. Algan, Y., \& Cahuc, P. (2013). Trust and Growth. Annual Review of Economics, (5), 521-549. https://doi.org/10.1146/annurev-economics-081412-102108

3. Alshaora, M., Greggb, D., \& Ramirez, R. (2017). Virtual team effectiveness: The role of knowledge sharing and trust. Information \& Management, 54 (4), 479-490. https://doi. org/10.1016/j.im.2016.10.005

4. Aupers, S. (2012). Trust No One: Modernization, paranoia and conspiracy culture. European Journal of Communication, 27 (1). 22-34. https://doi.org/10.1177/0267323111433566

5. Ayoko, O. B. \& Pekerti, A. A. (2016). The mediating and moderating effects of conflict and communication openness on workplace trust. International Journal of Conflict Management, 9, 297-318. http://dx.doi.org/10.1108/10444060810909275

6. Azman, I., Afiqah, F. N., Madi, A. M., \& Huda, M. M. N. (2013). A Study of the Correlation between Training Administration and Training Motivation. Management \& Marketing. Challenges for the Knowledge Society, 8, 95-108.

7. Bjørnskov, C. (2012). How Does Social Trust Affect Economic Growth? Southern Economic Journal, 78 (4), 1346-1368. https://doi.org/10.4284/0038-4038-78.4.1346

8. Botsman, R. (2017). The collaborative economy: The new order of trust. Presentation at the Nordic Business Forum, Helsinki.

9. Chinn, S., Lane, D. S., \& Hart, P. S. (2018). In consensus we trust? Persuasive effects of scientific consensus communication. Public Understanding of Science, 27 (7), 807-823. https://doi. org/10.1177/0963662518791094

10. Dalkir, K. (2011). Knowledge Management in Theory and Practice. London: Routledge. http://dx.doi. org/10.4324/9780080547367

11. Elchardus, M., \& De Keere, K. (2013). Social control and institutional trust: Reconsidering the effect of modernity on social malaise. The Social Science Journal 50 (1), 101-111. https://doi. $\operatorname{org} / 10.1016 /$ j.soscij.2012.10.004

12. Ellonen, R., Blomqvist, K., \& Puumalainen, K. (2008). The Role of Trust in Organisational Innovativeness. European Journal of Innovation Management, 11 (2), 160-181. http://dx.doi. org/10.1108/14601060810869848

13. Ford, D. P. (2003). Trust and knowledge management: the seeds of success, in Holsapple, C. W. (Ed.): Handbook on Knowledge Management, Springer-Verlag, Berlin, Heidelberg, 1, 553-575. 
14. Gonzales, R. V. D., \& Martins, M. F. (2017). Knowledge Management Process: a theoreticalconceptual research. Gestão \& Produção, 24 (2), 248-265. https://doi.org/10.1590/0104530x0893-15

15. Hofstede, G., Hofstede, G.J., \& Minkov, M. (2010). Cultures and Organizations: Software of the Mind. New York: McGraw-Hill.

16. Jakubik, M. (2007). Exploring the Knowledge Landscape: four emerging views of knowledge. Journal of Knowledge Management, 11 (4), 6-19. https://doi.org10.1108/13673270710762675

17. Jakubik, M. (2011). Becoming to know. Shifting the knowledge creation paradigm. Journal of Knowledge Management, 15 (3), 374-402. http://dx.doi.org/10.1108/13673271111137394

18. Killingsworth, B., Xue, Y., \& Liu, Y. (2016). Factors influencing knowledge sharing among global virtual teams. Team Performance Management, 22 (5-6), 284-300. http://dx.doi. org/10.1108/TPM-10-2015-0042

19. Kraft, P. W., Lodge, K. M., \& Taber, Ch. S. (2015). Why People Don't Trust the Evidence: Motivated Reasoning and Scientific Beliefs. The ANNALS of the American Academy of Political and Social Science, 658 (1), 121-133. https://doi.org/10.1177/0002716214554758

20. Kuo, T. (2013). How expected benefit and trust influence knowledge sharing. Industrial Management \& Data Systems, 111 (4), 506-522. https://doi.org/10.1108/02635571311322766

21. Lazanyi, K. (2017). Innovation - the role of trust. Serbian Journal of Management, 12 (2), 331-344. https://doi.org/10.5937/sjm12-12143

22. Lazanyi, K., Cepel, M., \& Bilan, S. (2017). Comparison of Trust and Social Relations among Students in Russian and Hungarian Higher Education. Economics and Sociology, 10 (4), 162-174. https://doi.org/10.14254/2071-789X.2017/10-4/13

23. Lencioni, P. (2017). The untapped advantage of organisational health. Presentation at the Nordic Business Forum, Helsinki.

24. Linand, R., \& Hsiao, J. (2014). The Relationships between Transformational Leadership, Knowledge Sharing, Trust and Organizational Citizenship Behaviour. International Journal of Innovation, Management and Technology, 5 (3), 171-174. https://doi.org/10.7763/IJIMT.2014. V5.508

25. Nonaka, I. (1994). A dynamic theory of knowledge creation. Organisational Science, 5 (1), 14-37.

26. Nonaka, I. \& Takeuchi, H. (1995). The Knowledge Creating Company. How Japanese Companies Create the Dynamics of Innovation. Oxford: Oxford University Press. https://doi.org/10.1016/B978-07506-7009-8.50016-1

27. Nonaka, I., Toyama, R. \& Konno, N. (2000). SECI, Ba and Leadership: a Unified Model of Dynamic Knowledge Creation. Long Range Planning, 33 (1), 5-34.

28. Nonaka, I., Toyama, R., \& Hirata, T. (2008). Managing Flow. A Process Theory of the KnowledgeBased Firm. London: Palgrave Macmillan. http://dx.doi.org/10.1057/9780230583702

29. O'Neill, O. (2018). Linking Trust to Trustworthiness. International Journal of Philosophical Studies, 26 (2), 293-300. https://doi.org/10.1080/09672559.2018.1454637 
30. Paliszkiewicz, J., \& Koohang, A. (2013). Organizational trust as a foundation for knowledge sharing and its influence on organizational performance. Online Journal of Applied Knowledge Management, 1 (2), 116-127.

31. Paliszkiewicz, J., Koohang, A., \& Nord, J. H. (2014a). Management trust, organisational trust, and organisational performance: Empirical validation of an instrument. Online Journal of Applied Knowledge Management, 2 (1), 28-39.

32. Paliszkiewicz, J., Koohang, A., Gołuchowski, J., \& Nord, J. H. (2014b). Management Trust, Organisational Trust, and Organisational Performance: Advancing and Measuring a Theoretical Model. Management and Production Engineering Review, 5 (1), 32-41.

33. Polanyi, M. (1966). The Tacit Dimension. London: Routledge and Kegan Paul.

34. Pols, H. A. P. (2015). Empirical studies on the economic impact of trust. Rotterdam: Erasmus Research Institute of Management

35. Rahman, M. S., Osman-Gani, A. M., Momen, M. A., \& Islam, N. (2015). Testing knowledge sharing effectiveness: trust, motivation, leadership style, workplace spirituality and social network embedded model. Management \& Marketing. Challenges for the Knowledge Society, 10 (4), 284-303. https://doi.org/10.1515/mmcks-2015-0019

36. Rutten, W., Blaas-Franken, J. \& Martin, H. (2016). The impact of (low) trust on knowledge sharing. Journal of Knowledge Management, 20 (2), 199-214. https://doi.org/10.1108/JKM-102015-0391

37. Sankowska, A. (2013). Relationships between Organisational Trust, Knowledge Transfer, Knowledge Creation and Firm's Innovativeness. Learning Organisation, 20 (1), 85-100. https:// doi.org/10.1108/09696471311288546

38. Serenko, A. (2013). Meta-analysis of scientometric research of knowledge management: discovering the identity of the discipline. Journal of Knowledge Management, 17 (5), 773-812. https://doi.org/10.1108/JKM-05-2013-0166

39. Tan, H. H., \& Lim, A. K. H. (2009). Trust in Co-workers and Trust in Organisations. The Journal of Psychology, 143 (1), 45-66. https://doi.org/10.3200/JRLP.143.1.45-66

40. von Krogh, G., Ichijo, K., \& Nonaka, I. (2000a). Enabling Knowledge Creation. How to Unlock the Mystery of Tacit Knowledge and Release the Power of Innovation. Oxford: Oxford University Press.

41. von Krogh, G., Nonaka, I., \& Nishiguchi, T. (2000b). Knowledge Creation. A Source of Value. London: McMillan Press.

42. Yong, W. K., \& Jaekvon, K. (2014). HR Practices and Knowledge Sharing Behaviour: Focusing on the Moderating Effect of Trust in Supervisor. Public Personnel Management, 43 (4), 387-414. https://doi.org/10.1177/0091026014542342

43. Zanini, M. T., \& Musante, M. (2013). Trust in the knowledge economy. Journal of Business \& Industrial Marketing, 28 (6), 487-493. https://doi.org/10.1108/JBIM-04-2013-0102 


\section{Contact information}

prof. dr. habil Andrea Bencsik, CSc., Ph.D.

J. Selye University, University of Pannonia

Faculty of Economics and Informatics, Faculty of Business and Economics

Department of Management

Hungary

E-mail:bencsika@ujs.sk; bencsik.andrea@gtk.uni-pannon.bu

ORCID: 0000-0001-8204-3706

Dr. Maria Jakubik, PhD.

Ronin Institute Montclair

USA

E-mail:maria.jakubik@@ronininstitute.org

Dr. Timea Juhasz, Ph.D.

Budapest Business School

Faculty of International Management and Business

Department of Social Science Methodology

Hungary

E-mail:juhas:.timea@uni-bge.bu

ORCID: 0000-0001-5386-0678 